\title{
Correction to: Synergistic killing effects of homoharringtonine and arsenic trioxide on acute myeloid leukemia stem cells and the underlying mechanisms
}

\author{
Ming Tan ${ }^{1}$, Qian Zhang ${ }^{1,2}$, Xiaohong Yuan ${ }^{1}$, Yuanzhong Chen ${ }^{1 *}$ and Yong $\mathrm{Wu}^{1 *}$
}

\author{
Correction to: J Exp Clin Cancer Res \\ https://doi.org/10.1186/s13046-019-1295-8
}

In the publication of this article [1], there are two corrections: 1. The corresponding author Yuanzhong Chen's email should be changed to chenyz@mail.fjmu.edu.cn; 2. Several figures Fig. 5, Fig. 8, and Additional files 5, 6, 9 and 10 need to be corrected, because the formats are wrong, and the revised figures are shown below.

The original article has been corrected.

\section{Additional files}

Additional file 5: Figure S5. Homoharringtonine $(\mathrm{HHT})$ combined with arsenic trioxide (ATO) decrease the proportion of primary leukemia stem cells (LSCs) in serum free medium with cytokine cocktail (FIt3L, SCF, IL-3 and IL-6). Quantification of frequencies of CD34+cells (A), CD34+/CD38 -cells (B) and CD34+/CD38-/CD96+ cells (C) from patient 4. (D) Display of flow cytometric analysis on bone marrow sample after treatment with HHT and ATO alone or combined.

Additional file 6: Figure S6. Homoharringtonine $(\mathrm{HHT})$ combined with arsenic trioxide (ATO) more effectively damaged the primary CD34+CD38 - cells than CD34+/CD38+ cells in serum-free medium with a cytokines cocktail (Flt3L, SCF, IL-3 and IL-6). (A-C) Quantification of frequencies of Annexin V-positive cells in CD34+CD38- and CD34+CD38+ cells from patient 1 (A), patient 2 (B), patient $3(C)$, patient 4 (D). (E) Representative flow cytometric analysis of patient 2 for apoptosis using Annexin $V$ and stem cells markers (CD34, CD38).

Additional file 9: Table S1. Patients characteristic.

Additional file 10: Table S2. Primer Sequences for PCR.

\section{Author details}

${ }^{1}$ Fujian Institute of Hematology, Fujian Provincial Key Laboratory on Hematology, Fujian Medical University Union Hospital, 29 Xinquan Road, Fuzhou 350001, Fujian, China. ${ }^{2}$ Fujian Medical University graduate school, 1 Xuefu North Road, Fuzhou 350112, Fujian, China.

\footnotetext{
*Correspondence: chenyz@mail.fjmu.edu.cn; wuyong9195@126.com

${ }^{1}$ Fujian Institute of Hematology, Fujian Provincial Key Laboratory on Hematology, Fujian Medical University Union Hospital, 29 Xinquan Road, Fuzhou 350001, Fujian, China

Full list of author information is available at the end of the article
}

Published online: 16 September 2019

\section{Reference}

1. Tan, et al. Synergistic killing effects of homoharringtonine and arsenic trioxide on acute myeloid leukemia stem cells and the underlying mechanisms. J Exp Clin Cancer Res. 2019;38:308 https://doi.org/10.1186/s13 046-019-1295-8.

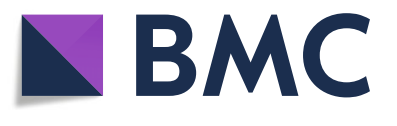

(c) The Author(s). 2019 Open Access This article is distributed under the terms of the Creative Commons Attribution 4.0 International License (http://creativecommons.org/licenses/by/4.0/), which permits unrestricted use, distribution, and reproduction in any medium, provided you give appropriate credit to the original author(s) and the source, provide a link to the Creative Commons license, and indicate if changes were made. The Creative Commons Public Domain Dedication waiver (http://creativecommons.org/publicdomain/zero/1.0/) applies to the data made available in this article, unless otherwise stated. 


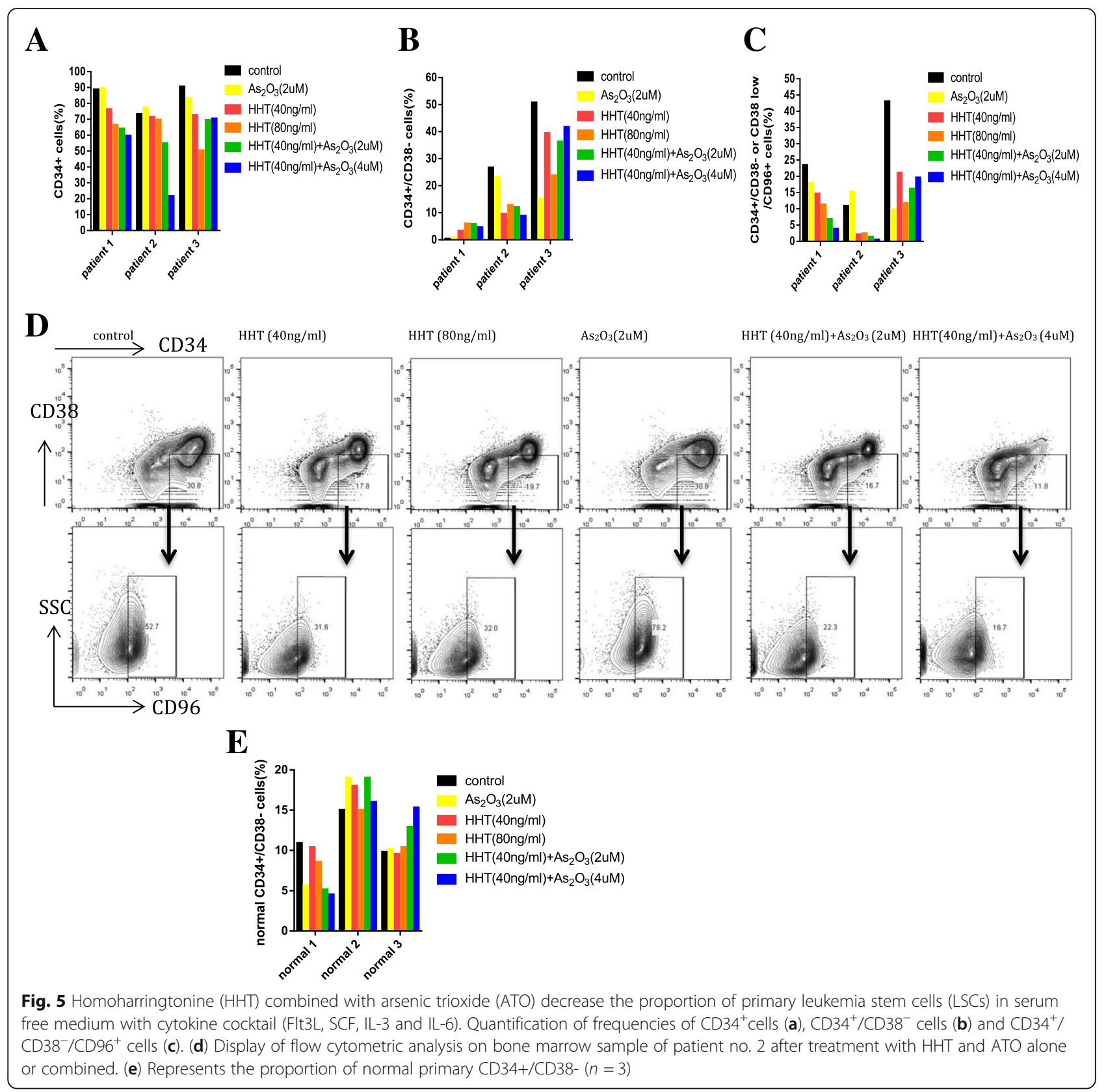



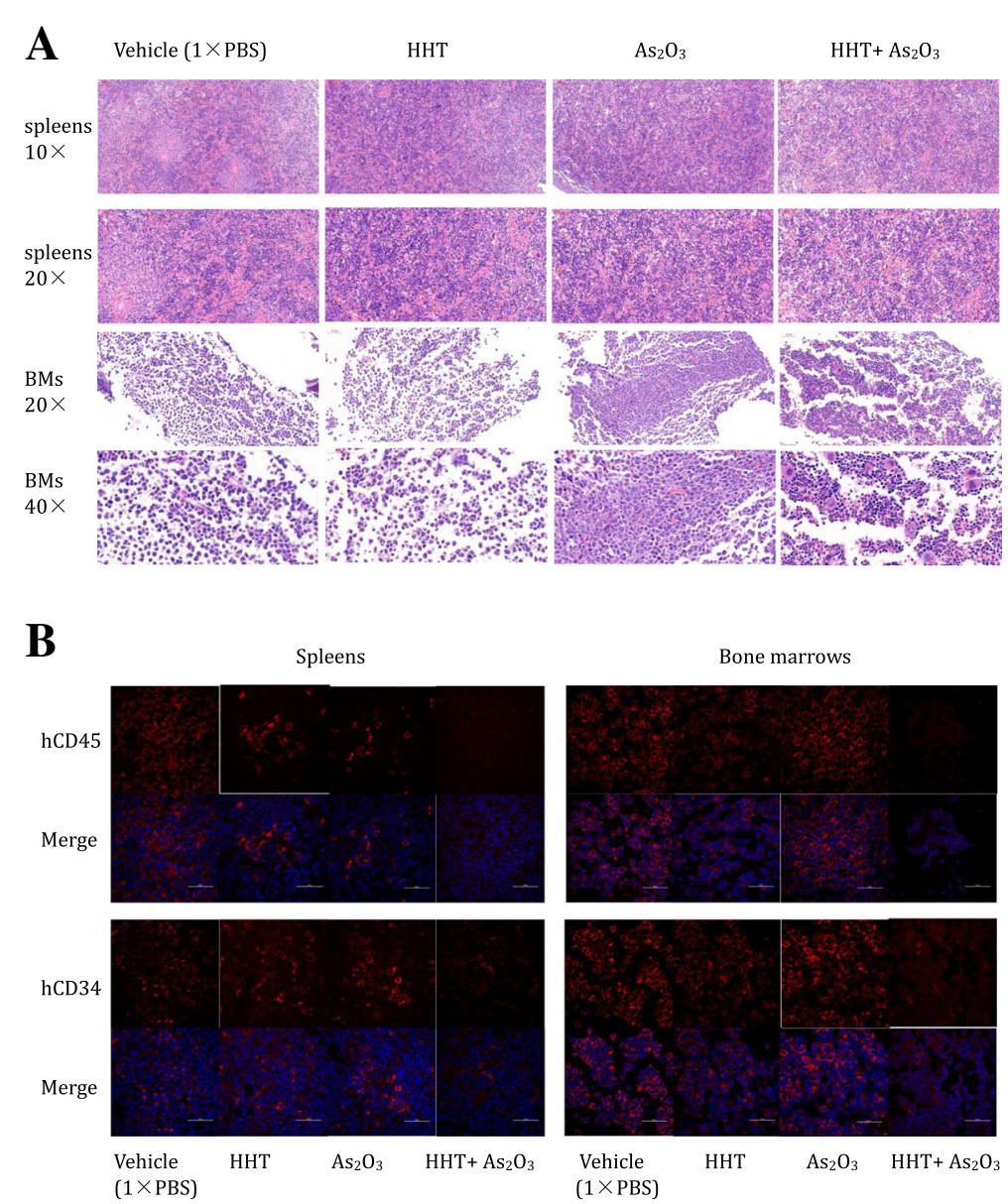

Fig. 8 Homoharringtonine (HHT) combined with arsenic trioxide (ATO) remarkably obliterated the histological infiltration of leukemia stem cells (LSCS). (a) H\&E-stained sections of representative 4\% paraformaldehyde-fixed spleens and bone marrow from NRG mice. (b) hCD45 and hCD34 levels were detected in the different groups by confocal laser-scanning microscopy in representative 4\% paraformaldehyde-fixed spleens and bone marrow samples from NRG mice. Scale bars: $50 \mu \mathrm{m}$ 

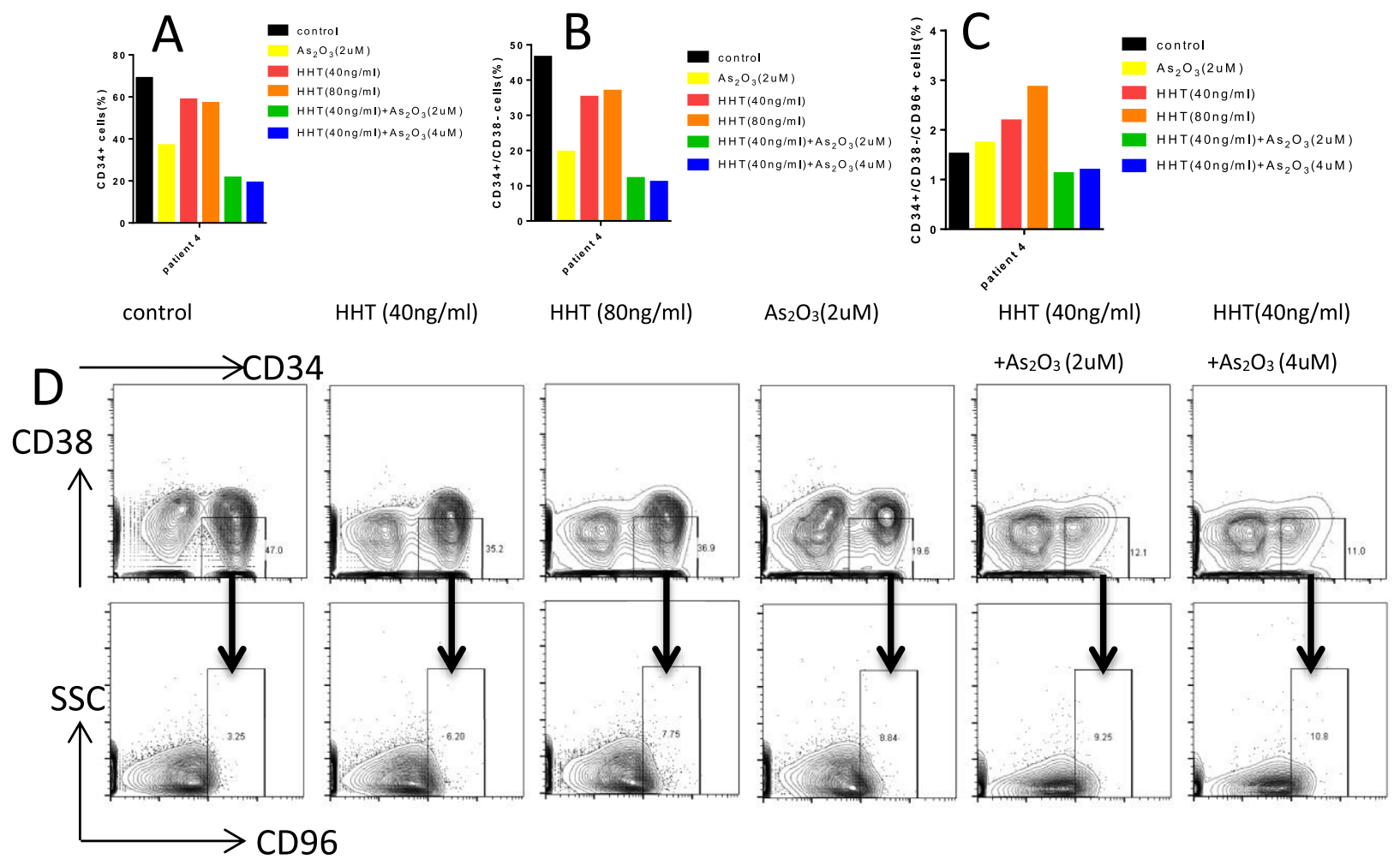

Fig S5.

Fig. S5 Homoharringtonine (HHT) combined with arsenic trioxide (ATO) decrease the proportion of primary leukemia stem cells (LSCs) in serum free medium with cytokine cocktail (Flt3L, SCF, IL-3 and IL-6). Quantification of frequencies of CD34 $4^{+}$cells (A), CD34 $/ 4^{+}$CD38 cells (B) and CD34 $/$CD38 $/$ $\mathrm{CD}^{+}{ }^{+}$cells (C) from patient 4. (D) Display of flow cytometric analysis on bone marrow sample after treatment with HHT and ATO alone or combined 

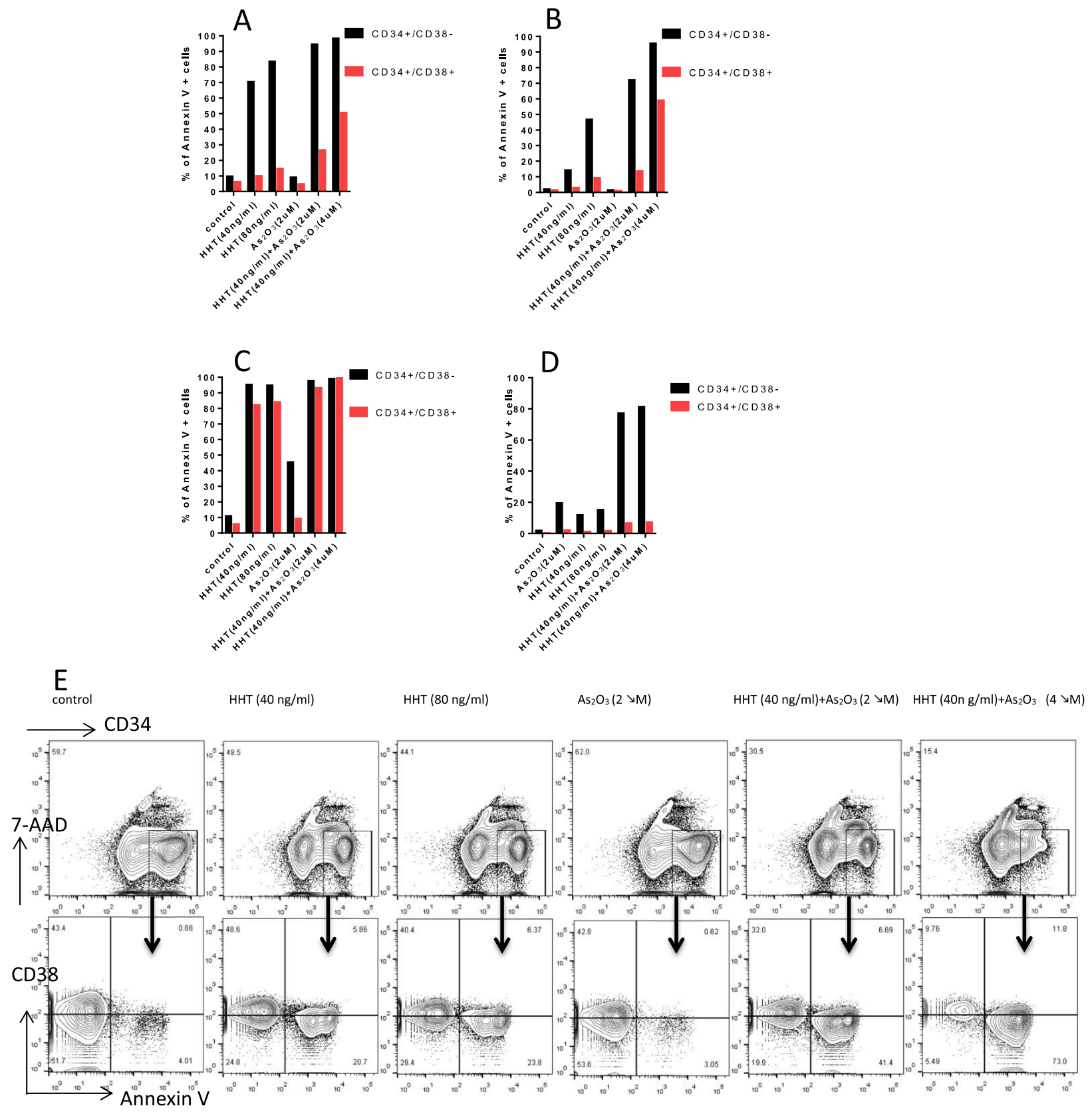

Fig. S6.

Fig. S6 Homoharringtonine (HHT) combined with arsenic trioxide (ATO) more effectively damaged the primary $\mathrm{CD}_{3} 4^{+} \mathrm{CD} 38^{-}$cells than $\mathrm{CD} 34^{+} / \mathrm{CD}^{-} 8^{+}$ cells in serum-free medium with a cytokines cocktail (FIt3L, SCF, IL-3 and IL-6). (A-C) Quantification of frequencies of Annexin V-positive cells in $\mathrm{CD}_{4}{ }^{+} \mathrm{CD} 38^{-}$and $\mathrm{CD} 34^{+} \mathrm{CD} 38^{+}$cells from patient 1 (A), patient 2 (B), patient 3 (C), patient 4 (D). (E) Representative flow cytometric analysis of patient 2 for apoptosis using Annexin $V$ and stem cells markers (CD34, CD38) 
Table S1 Patients characteristic

\begin{tabular}{|c|c|c|c|c|c|c|c|c|c|}
\hline NO. & Gender & Age & $\mathrm{WBC}\left({ }^{*} 10^{9} / \mathrm{L}\right)$ & $\mathrm{Hb}(\mathrm{g} / \mathrm{L})$ & $\mathrm{PLT}\left({ }^{*} 10^{9} / \mathrm{L}\right)$ & FAB type & BM Blasts(\%) & Immune markers & Karyotype \\
\hline 1 & female & 23 & 1.85 & 124 & 168 & Mo & 63.2 & CD7, CD117, HLA-DR & $46 X X$ \\
\hline 2 & male & 29 & 12.72 & 138 & 7 & M5 & 60.3 & CD7,HLA-DR, CD33 & $46 X Y$ \\
\hline 3 & male & 32 & 1.14 & 46 & 4 & $\mathrm{M} 2 \mathrm{a}$ & 80 & MPO,CD99,CD117 & $46 X Y t(8 ; 21)$ \\
\hline 4 & female & 36 & 5.57 & 50 & 83 & M5b & 78 & CD117, CD33,MPO & $46 X X$ \\
\hline 5 & female & 43 & 20.57 & 45 & 10 & M1 & 72 & CD117, CD33, MPO & $46 X X$ \\
\hline 6 & female & 25 & 19.6 & 34 & 23 & MO & 69.3 & CD7, CD117, MPO & $46 X X$ \\
\hline 7 & male & 29 & 27 & 23 & 3 & M5 & 59.6 & CD33, HLA-DR CD15 & $46 X Y$ \\
\hline
\end{tabular}

NO.1-4 were used to FCM (Flow Cytometry) analysis; NO.5-7 were used to synergistic effect. NO.7 were also used for WB

Table S2 Primer Sequences for PCR

\begin{tabular}{ll}
\hline Gene & Primer Sequences \\
\hline -actin & Forward 5'-GCCAACCGCGAGAAGATGA-3' \\
& Reverse 5'-CATCAGGATGCCAGTGGT-3' \\
CD34 & Forward 5'- ACTCGGTGCGTCTCTCTAGG -3' \\
& Reverse 5'- CCGTGAGACTCTGCTCTGC-3' \\
CD38 & Forward 5'- TTG GGA ACTCAG ACC GTA CCT TG-3' \\
& Reverse 5'- CCA CAC CAT GTGAGG TCA TC-3' \\
CD96 & Forward 5'- ACCACAGTCAAGGTTTTTG-3' \\
& Reverse 5'- CCAGGCTGGAGAAGGTTGG-3' \\
\hline
\end{tabular}

